masia dolens are met with, when so much care is taken to im. poverish the blood and weaken the nervous system.

In the same spirit as the foregoing we find vaginal injections of warm milk-and-water advised for the relief of pruritus of the valva. (pp. 55, 56.) This is simply one of the remnants of barbarism; of the time when the various parts of animals or their excretions were employed in medicine. But just as the use of urine and milk to inflamed eyes has long since been laughed at, so we cannot but regard Dr. Churchill's formula as useless, and therefore injudicious.

The misprints are numerous. Thus, amongst many others, we have-c"Pallas, Linnæus, and Percy calls them." (p. 282.) "Her constitution was breaking down, without hope or help from medicine or surgery." (p. 80.) "It" (urethritis) "may be acute or chronic according to the time we are called in." (p. 81.) "The rigidity and persistence of the hymen is mentioned." (p. 97.) "The probabilities of cure has been." (p. 120.) "The diagnosis is seldom difficult. We may expect this to be the case when we find the orifice of the vagina," \&c. (p. 127.) "A recent writer has enumerated among the symptoms or consequences of leucorrhœea, disturbance of the menstrual functions, generally its too frequent recurrence, and is at a loss to explain them. If he had not rejected the distinction between uterine and vaginal leucorrhoea, he would have been at no loss to do so," \&c. (p. 133.) "The causes (say Dr. Locock) of this condi. tion." (p. 190.) "Subsequently a binder must be applied, and the patient managed as after ordinary labour, but special reference to the flooding." (p. 288.) "Professor Dubois denies that these displacements ordinarily lead to the consequences which have been attributed to it." (p. 411.)

There are many other passages which we had marked for notice-some for approval, some for censure; but it is unneces. sary to say more. Few men should be better able, from their own experience, to write a good book on the Diseases of Women than Dr. Churchill ; but to produce a really useful work, fully up to the knowledge existing at the time of going to press, he must exercise more patience and judgment, and give more real labour to his task than he seems to have done in preparing this new edition.

The Principles and Methods of Medical Observation and Research. For the Use of Advanced Students and Junior Practitioners. Second Edition, with Copious Nosologies and Indices of Fevers, and of Constitutional Cutaneous, Nervous, and Mental Diseases. By THomas LAycock, M.D., F.R.S.E., F.R.C.P., Professor of the Practice of Medicine in the University of Edinburgh, \&c. \&c. pp. 403 Edinburgh : Maclachlan and Stewart. London: Simpkin, Marshall, and Co.

THE fact that a book has reached a second edition may be taken as a proof of important merits and uses. The praise of the public implied in the purchase of a first edition leaves the reviewer little else to do than to point out faults. It is clearly desirable that students should read once for all a good statement of "The Principles and Methods of Medical Observation and Research ;" and thanks are due to Professor Laycock for conceiving and carrying out such a statement. We think, however, it has several faults. It is tediously long and diffuse in consequence of a redundant verbosity and an unnecessary amplification of much that is obvious and well understood. It is got up too expensively for a student's book, with backs and margins rather becoming the drawing-room than the studyan evil, by the way, which is becoming very common.

The author, in the Preface, calls particular attention to an entirely new Part, containing the nosologies of several important groups of diseases. We do not see the perfect appropriateness of a nosology in such a book. Besides which, this particular nosology is so elaborate and exhaustive, so intricate, not to say confused, that either to be led by it, or not misled, would require a detailed knowledge of pathology and other nosologies such as can scarcely be expected of a student. As to the information conveyed in it, it is too fragmentary to be of use ; and as to the mental exercise implied in following out the termi. nology of it, this would be rather a lexicographical surfeit than a beneficial act of medical training. With these qualifications we commend the book to advanced students and junior practitioners.

\section{THE FATALITY OF FROST.}

\section{To the Editor of The Lancet.}

SIR,-I read with much interest an article which appeared in your journal of Jan. 23rd, on the "Fatality of Frost." As I am still sceptical on that subject to a great extent, permit me to make a few additional observations. In large towns and cities like London, where the streets, even in intensely cold weather, are damp under foot, in consequence of the im. mense amount of traffic along the pavements, affections of the chest increase, and so evidently does the mortality, according to the Registrar-General's reports. But in country districts, where the roads and streets remain perfectly dry under foot, diseases of the chest do not increase, and the mortality during the continuation of severe frost actually diminishes. In December, 1860, having charge of an extensive country union and private practice, I enjoyed during the intense frost a fortnight or so of recreation with my friends in the neighbourhood; whereas previously we were busily employed. The mortality in a town of three thousand inhabitants was reduced to one, and that one was an old person whose demise had been expected some time before. The ground was covered with snow in a crisp frozen state, yet few thought of wearing flannel underclothing. In about a fortnight after the commencement of the thaw sickness and mortality rapidly increased, and we had as much work as we could manage. The healthy state of the neighbourhood during the continuation of the frost was so striking, that our learned and highly respected pastor, in preaching the funeral sermon of the aged person already mentioned, commented at length on the fact, and he particularly drew attention to the low rate of mortality.

From personal experience I know that damp feet cause pec toral complaints, but I question whether mere cold has much influence in doing so. At all events, moisture is the great enemy. It is well known that a man may pass from a dry heated room into a cold dry place without any danger what ever; but when moisture is introduced it alters the question. In 1860, during the frost, I did not feel the want of flannel under-clothing, although I am subject to bronchitis at times. I am more afraid of damp feet than anything else. Even many elderly persons have not required any extra clothing this winter, in spite of the sharp frost. I have not worn any flannel or extra clothing excepting a top-coat this winter, although I frequently went from near a large fire directly into the cold air, merely putting on my over-coat. I have for many years noticed that in dry, calm, very frosty weather my work has always been lessened; whereas, whenever there is moisture, whether it be winter or summer, sickness always increases proportionately. In very frosty weather the air is usually still, and people in health do not require much extra clothing; but during stormy weather, especially in travelling against the wind, people become much more susceptible to catarrh and chest complaints, and extra (flannel) clothing to protect the chest should then be worn. When flannel is once had recourse to it cannot be left off with impunity. I quite agree with you as regards your benevolent remarks in sympathy with the poor at this time of the year. The thaw, in my humble opinion, has much more to do with the increase of sickness than our welcome Christmas frost.

Liverpool, Jan. 1864

I am, Sir, yours very obediently,

Chloroform.-Professor Nussbaum has succeeded in prolonging the anæsthesia induced by chloroform, by the sub. cutaneous injection of a solution containing one grain of acetate of morphia. In one case the patient slept twelve hours, and underwent a painful operation without experiencing any sensation whatever. The injection performed witho'it the previous inhalation of chloroform produced no such effect. 